\title{
Development of the University's Business Model with the Use of a Digital Learning Platform
}

\author{
Oksana Yu. Iliashenko \\ Institute of Industrial Management \\ Economics and Trade \\ Peter the Great Saint Petersburg \\ Polytechnic University \\ Saint Petersburg, Russia \\ ioy120878@gmail.com
}

\author{
Zilia U. Bikkulova \\ Institute of Industrial Management \\ Economics and Trade \\ Peter the Great Saint Petersburg \\ Polytechnic University \\ Saint Petersburg, Russia \\ bikkz@yandex.ru
}

\author{
Alissa Dubgorn \\ Peter the Great St.Petersburg \\ Polytechnic University; \\ Graduate School of Business and \\ Management \\ Saint Petersburg, Russia \\ alissa.dubgorn@gmail.com
}

\begin{abstract}
The objective of the current research was development of the university business model using a digital learning platform. In the framework of the current research, following methods have been used: analysis and modeling. Text sources were analyzed in order to make an overview of studies in the field. The modeling has been conducted in order to show how the university business model changes with transition to a digital platform. As the result of the research, a literature overview regarding digital learning platforms has been made; a university business model canvas before implementation of the digital platform has been developed; structure of a digital learning platform has been modeled; a university business model canvas after implementation of the digital platform has been developed. The main changes between the models have been described with comments based on experience of organizations. Developed business model can be used while implementing digital platforms in educational organizations.
\end{abstract}

Keywords—digital platform, business model, education

\section{INTRODUCTION}

Nowadays, universities seeking to maintain their position in the global education market face the task of entering the international scientific and educational space. In order to solve this task, universities must undergo a digital transformation [1]. The face of education is being significantly changed by digital learning platforms, and it concerns all educational spheres and organization types. In recent years, there is active discussion surrounding digital learning platforms and their benefits.

A digital learning platform is a piece of software designed to heavily assist during the educational process. There are a range of options available depending on the specific needs of the institution. They include: learning management systems (LMS), learning content management systems (LCMS), as well as virtual classroom tools and virtual learning environments (VLE) [2].

The objective of the current research was development of the university business model using a digital learning platform. A business model describes the rationale of how an organization creates, delivers, and captures value, in economic, social, cultural or other contexts $[3,4]$.

\section{METHODS OF THE RESEARCH}

In the framework of the current research, following methods have been used:
- Analysis. Text sources were analyzed in order to make an overview of studies in the field.

- Modeling. The modeling has been conducted in order to show how the university business model changes with transition to a digital platform.

\section{LITERATURE OVERVIEW}

The topic of digital learning is covered in many studies all over the world. There are studies on digital learning ecosystem in the educational organization. A learning ecosystem is a system of people, content, technology, culture, and strategy, existing both within and outside of an organization, all of which has an impact on both the formal and informal learning that goes on in that organization. Just like a living ecosystem, a learning ecosystem can be healthy or sick, nurtured or threatened, self-sustaining or endangered. Achieving the development goals, then, requires an organization to be aware of its own ecosystem, including its parts and the internal and external forces that shape them [5, 6]. Regarding an educational organization, a learning ecosystem can be defined as an environment where the students and the teachers interact in an organic way to construct learning experiences. The authors of the studies research into the components of a learning ecosystem in the digital age [7], present digital learning ecosystem as a new vision of learning [8] and offer models for digital learning ecosystem $[9,10]$. There are also articles on digital platforms devoted to their benefits and challenges [11] and offering platform architectures and technical solutions for them $[12,13,14]$.

\section{RESUlTS OF THE RESEARCH}

In the framework of this research, we developed two business models of a university: first one shows the university without digital platform, second shows the university using it.

Generally, a business model can be defined as a plan for the successful operation of a business, identifying sources of revenue, the target customer base, products, and details of financing. Essentially it aims to tell how the key drivers of a business fit together $[15,16]$. In our research, both business models are developed using the business model canvas template by A. Osterwalder. The advantages of this template are following:

1) Focus. The business model canvas is designed to guide thinking through each of the key components or building blocks for devising a business model. In this respect it allows 
the business to understand how each aspect relates to the others; how the functions, activities and processes interlink and interlock. It allows thinking about the business in a more systematic and formal way, ensuring that each area is effectively covered to produce a more comprehensive and considered picture of the business.

2) Speed and agility. The key principle of the business model canvas is to concentrate on quality rather than quantity. It is about determining the key inputs to each building block. The construct of the canvas is simple and focused, hence quick to get started with, develop and iterate. It is a living document that should be tested and re-worked over time, fostering an agile mentality of planning, verification and iteration. At any point it is purely a set of hypotheses that need to be tested and validated with actual customers.

3) Common language. One more advantage of the business model canvas is that it creates a common reference and language that can be used to articulate, share and thereby gain feedback on each business model and its constituent parts. Its intuitive nature doesn't take any deciphering and is therefore easy to interpret and consume. It provides a straightforward yet transparent reference that can be used internally across teams, as well as externally with advisors, investors and partners.

The business model canvas is a starting point for discovering, building, ratifying and developing the organization's business model(s). There are other considerations to business success that are implied but not explicitly covered by the business model canvas such as: the level and nature of competition, roles and responsibilities, core competencies and capacities, and defining measurable goals; yet the business model canvas framework covers and connects the primary driving factors [17].

As mentioned before, the business model canvas reflects systematically on the business model of an organization, so it allows focusing on the business model segment by segment [18]. The segments are following:

1) Customer segments. It is to identify which customer is targeted by the organization. Main questions asked for identification: "For whom is the university creating values for?", "Who is the most important customer of the university?"

2) Value proposition. It is to identify value proposition offered by the organization that meets the need of its customer. It will help to distinguish the organization from the competition according to Osterwalder. Main questions asked for identification: "What core value does the university deliver to the customer?", "Which customer needs is the university satisfying?"
3) Key activities. It is to identify the activities that are crucial to deliver the business's value proposition. Main questions asked for identification: "What key activities does value proposition of the university require?", "What activities are most important in distribution channels, customer relationships, revenue stream, etc?"

4) Key resources. It is to identify the assets that are needed by the business to action its key activities. Main questions asked for identification: "What key resources does value proposition of the university require?", "What resources are important the most in distribution channels, customer relationships, revenue stream, etc?"

5) Key partnerships. It is to identify supplier relationships or strategic alliances that can help to achieve operation optimization. Main questions asked for identification: "Who are the key partners/suppliers of the university?", "What are the motivations for the partnerships?'

6) Channels. It is to identify method(s) used to reach the target customer of the organization. Main questions asked for identification: "Through which channels customers of the university want to be reached?", "Which channels work best? How much do they cost? How can they be integrated into the university's and its customers' routines?"

7) Customers relationships. It is to identify depending on each customer segment the organization should decide the appropriate relationship between the business and customer. Main questions asked for identification: "What relationship the target customer expects the university to establish?", "How can the university integrate that in its activity in terms of cost and format?"

8) Cost structure. It is to identify significant costs and identification of costly resources or activities. Main questions asked for identification: "What are the most cost for the university?" "Which key resources/activities are most expensive?"

9) Revenue streams. It is to identify income generated from customers in the identified segments. Main questions asked for identification: "For what value are customers of the university willing to pay?", "What and how do they recently pay?", "How would they prefer to pay?", "How much does every revenue stream contribute to the overall revenues?" $[19$, $20]$.

In the figure 1, you can see the business model canvas for the university before implementation of digital learning platform. 


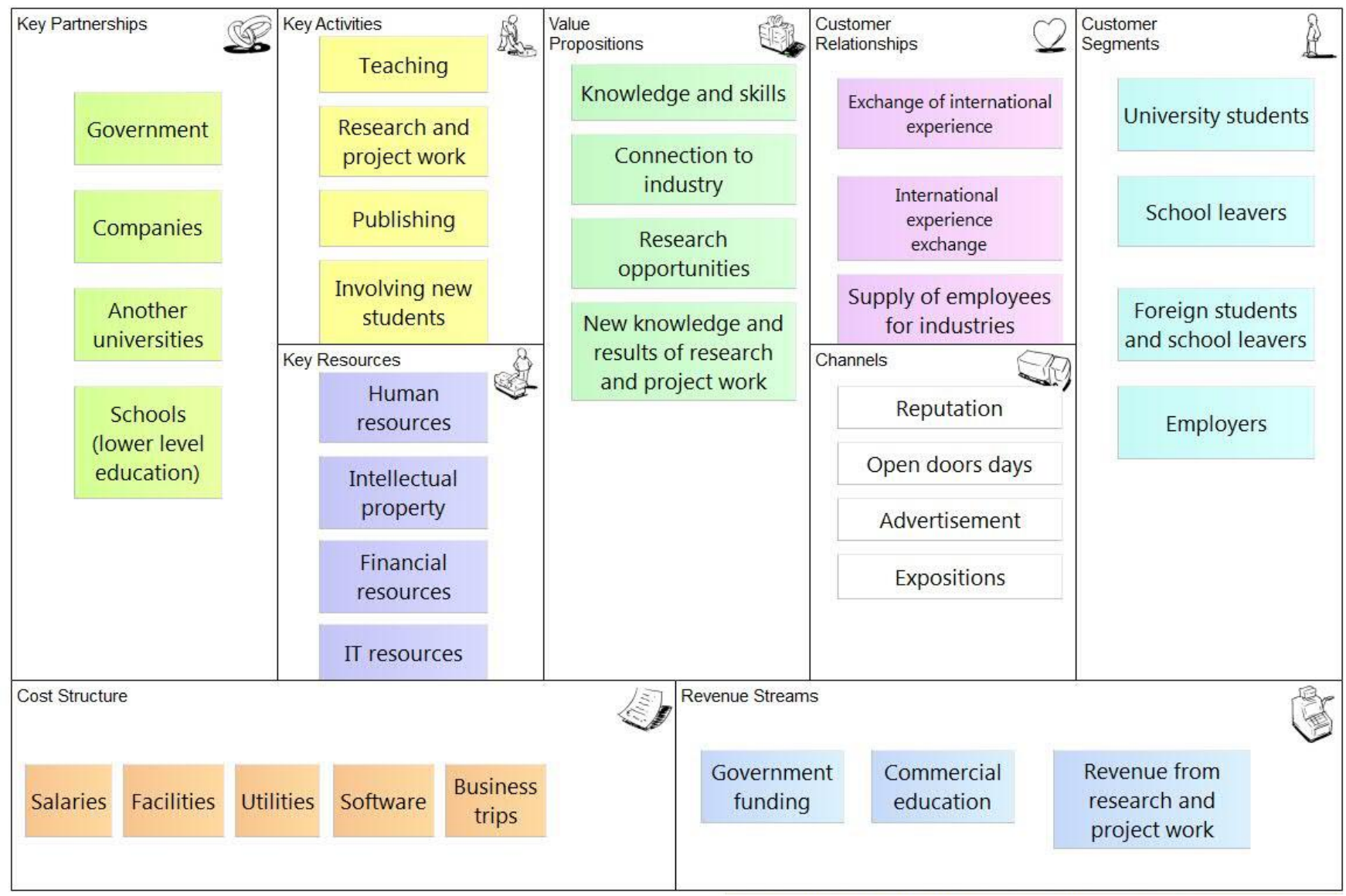

Fig. 1. Business model canvas (before implementation of the digital platform)

To define how the presented model can change after implementation of digital learning platform, we analyzed the general concept of digital learning platform and main components it consists of. As we mentioned earlier, a digital platform may consist of:

1) Learning management systems (LMS). An LMS is a set of integrated software services that organizes and supports online learning, education, and training. These systems usually provide content uploading and distribution, class administration, and discussion facilities (asynchronous threaded discussion and, less commonly, synchronous or 'chat' services). Some offer additional functionality such as assessment tools for online quizzing and testing; homework submission tools for managing the collection, grading, and redistribution of homework assignments to students in an online class; and student profiling to track the progress and performance of individual students using the system [21].

2) Learning content management systems (LCMS). An LMS and an LCMS are complementary but very different systems that serve different masters and address unique business challenges. The focus of an LCMS is on learning content. While an LMS is meant to provide content uploading and distribution, an LCMS gives the means to create elearning content more efficiently. The primary business problem an LCMS solves is to create just enough content just in time to meet the needs of individual learners or groups of learners [22].

3) Virtual classroom tools and virtual learning environments (VLE). A virtual learning environment is a collection of integrated tools enabling the management of online learning, providing a delivery mechanism, student tracking, assessment, and access to resources (JISC InfoNet 2004) [23]. A VLE is currently a Collaborative Virtual Environment (CVE), i.e. a computer-simulated place or space in which people can meet others to interact and work together [24].

In the figure 2, you can see possible structure of the digital platform. The figure presents a digital learning ecosystem of the university. It shows students and teachers interacting inside a VLE via an LCMS and an LMS (in turn, interacting between each other). The LCMS gives the teachers means to create content, which is supplied to students by the LMS. The green arrows show interaction regarding content and educational materials, while the yellow arrow shows interpersonal interaction between teachers and students which is also an inalienable part of the learning ecosystem.

In the figure 3, you can see the business model canvas for the university after implementation of digital platform. 


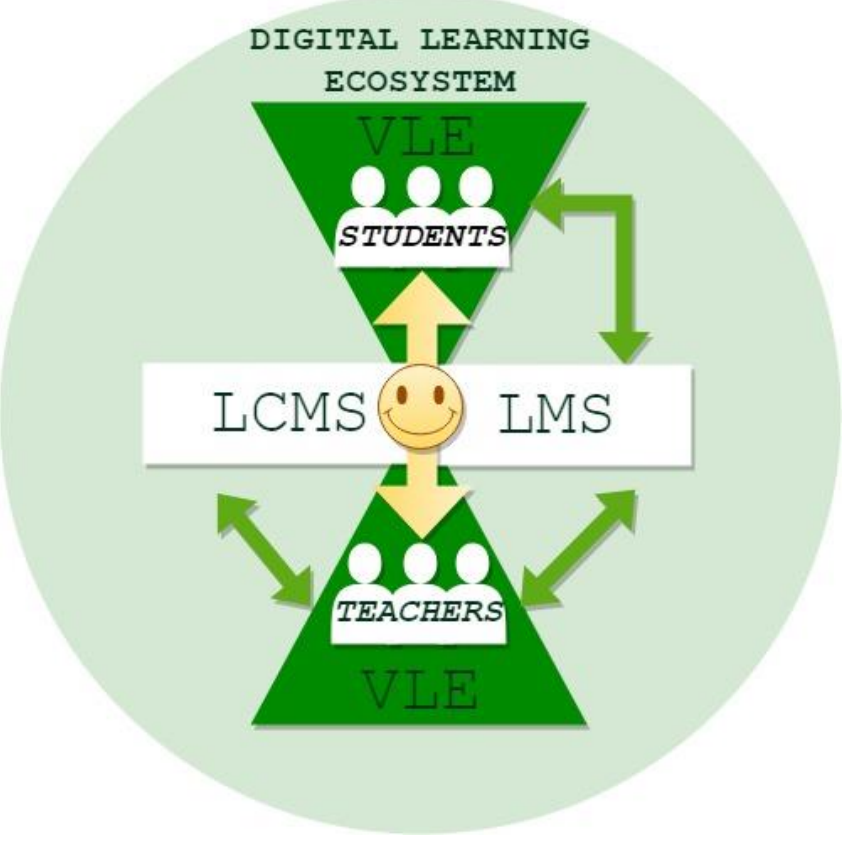

Fig. 2. Digital platform structure

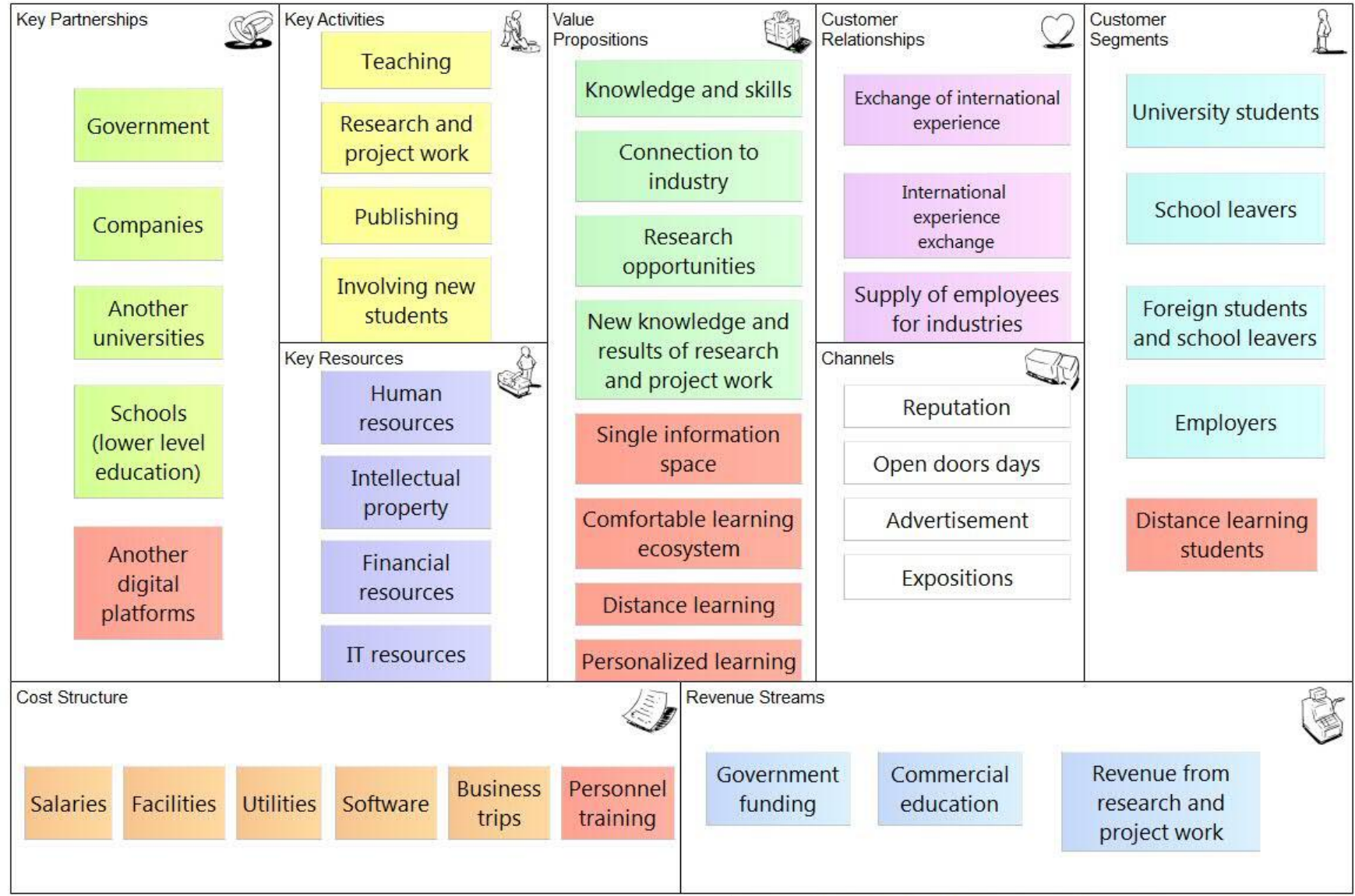

Fig. 3. Business model canvas (after implementation of the digital platform)

Next we will describe the main changes that are brought by implementation of a digital platform in the university, with comments based on experience of organizations. It should be noted that these changes will differ depending on specific features of a certain university and of a certain platform.
1) Changes in customer segments and relationships. A digital learning platform creates conditions for distance learning, therefore a new customer segment can be extracted - distance learning students. This segment may include students from faraway locations, as well as students who cannot attend classes personally because of health issues or 
other problems. Delivering courses online enables people in different geographic areas to take the same course at the same time, even collaborating on projects together. At the same time, as students of this segment study in the framework of the single digital platform using the same content, they will be in equal conditions with students of other segments. The International Chamber of Commerce (ICC) Academy, for instance, develops its courses in one central location and distributes them globally - allowing high-quality education to be available all over the world. Therefore, it is surely possible to say that a digital learning platform is able to break down barriers to education for any customer [25].

2) Changes in value proposition. First of all, a digital platform can propose the customers a single information space: it will accelerate coordination between all participants of the learning process, giving them access to the same up-todate information at the same time. Participants of the learning process will be able to exchange their knowledge and experience online and to request an advice or help from others. It will lead to the second value proposition a digital platform can add - comfortable learning ecosystem. With the assistance of a digital learning platform, the university can get benefitted from faster and clearer communication among all the people involved in education [26]. For example, teachers can provide students with instant results for assessments and learning exercises, which is significant in the modern world having a tendency of instant feedback expectation. This is very difficult to provide in a traditional classroom environment [27].

As mentioned before, distance learning can be a new value the university can provide after proper implementation of a digital platform.

Moreover, a digital platform can provide the opportunity of personalized learning, in order to help every student learn at the best pace and path for them and to help teachers monitor and manage an individual's progress model at scale. Students often perform better when they are able to take ownership of their progress in this way. They then have the freedom to revisit class materials they have struggled with, or skip through any sections they have already got a good grasp on. Also, students will be met with exercises that are tailored exactly for the level they are at. This is particularly helpful in blended learning environments. Therefore, digital learning can approximate the benefits of one on one tutoring while freeing up teachers to address other individual needs. The opportunity to customize learning sequences for each student will make process of learning more productive [27, 28].

3) Changes in key activities. Even if key activities of the university stay the same, there will be significant changes in the way they are realized. It will need time and efforts for the participants of the learning process to get accustomed to many their daily operations being digitalized. Moreover, quite a high extent of computer literacy and information culture will be expected from them, so the university should consider conduction of trainings on these subjects. The problem of adapting personnel to implementation of a digital platform cannot be neglected, and university should make its employees, as well as students, feel enough supported to use new technologies. All participants of learning process should see that all changes are justified and important to achieve certain goals; transition to a digital platform should be presented as a priority and determinant for success of the university [29, 30, 31, 32].

4) Changes in key resources. A digital platform can be considered as a new key IT-resource.

5) Changes in key partnerships. Partnership with other digital learning platforms (digital platforms of other universities and companies, online courses etc) via the university digital platform can be considered in order to provide additional opportunities for learning, professional improvement and internship. Collaboration between schools and teachers to merge expertise and resources, and better collaboration between learners, are a few of the most remarkable benefits of making use of a digital platform [26, 33].

6) Changes in cost structure. The implementation of a digital learning platform will need additional expenses, such as new software and personnel training. It should be noted that digital platforms come bundled with layers of expenses, and there are obvious costs (licensing fees, one-off setup fees, or pricing models) and hidden costs (setting up servers, customization, implementation of new processes, content creation) [34]. On the other hand, some costs may be reduced by decreasing time spent on coordination and management, by transformation of paper documents into electronic form and by reducing the number of hours and workload of teachers.

7) Changes in channels and revenue streams. Digital platforms assist increase school democracy and offer their students a voice, usually leading to a persuasive sense of school community [26]. All this will help to keep good reputation of the university and attract new students to it, as well as offering them new value propositions mentioned above. Hence it will lead to increase of income from commercial education. This income will also grow due to a new revenue stream from distance commercial students. Also, implementation of a digital platform will help the university to maintain its position in the global education market and to enter the international scientific and educational space, which will also lead to better reputation and, consequently, new revenues.

\section{DISCUSSION}

Based on the made literature overview, new tasks regarding implementation of digital platforms can be defined in more details and performed.

Developed business model can be used while implementing digital platforms in educational organizations.

The developed model has limitations, generally peculiar to the Osterwalder model. It does not substitute the whole business model planning, and is a rough sketch of a business model supposed to help draft multiple options quickly. In a real organization, the canvas needs to be updated constantly, and also it is necessary to map out business model options by creating multiple canvases $[35,36,37]$.

\section{CONCLUSION}

To sum up, we can conclude that a digital platform can brought many positive changes to a university being implemented properly. The most general business model changes coming with a digital learning platform were considered in this research. However, there may be 
differences depending on conditions of each university and related to each platform. Therefore, the offered models may need reconsideration and surely need constant update.

The structure of a digital platform is showed in general terms and shows only the necessary elements and relations between them. For development of the platform, elements may be added. It should be noted that digital learning platform technology is ever-developing today: it is getting faster, more secure, and convenient to use, and it easily gets integrated with other third-party systems in order to create a much more comprehensive studying environment for teachers and students [26, 38].

In the framework of the research, following tasks have been performed:

- A literature overview regarding digital learning platforms has been made.

- A university business model canvas before implementation of the digital platform has been developed.

- Structure of a digital learning platform has been modeled.

- A university business model canvas after implementation of the digital platform has been developed. The main changes between the models have been described with comments based on experience of organizations.

\section{ACKNOWLEDGMENT}

The reported study was funded by RSCF according to the research project № 19-18-00452.

\section{REFERENCES}

[1] Digital University: the use of digital technology in modern educational institutions. // Website IT Week. - 2017. - URL: https://www.itweek.ru/idea/article/detail.php?ID=192831. - (accessed July, 11, 2019)

[2] Why Teachers Love Digital Learning Platforms. // Website Dexway. URL: https://www.dexway.com/why-teachers-love-digital-learningplatforms/. - (accessed July, 11, 2019)

[3] Business model. // Wikipedia - the free encyclopedia. - 2019. - URL https://en.wikipedia.org/wiki/Business_model. - (accessed July, 11, 2019)

[4] I. Ilin, O. Kalinina, O. Iliashenko, A. Levina, Sustainable Urban Development as a Driver of Safety System Development of the Urban Underground (2016) Procedia Engineering, 165, pp. 1673-1682. DOI: 10.1016/j.proeng.2016.11.909

[5] What is a Learning Ecosystem? And How Does it Support Corporate Strategy? // Website Ej4. - 2018. - URL: https://www.ej4.com/blog/what-is-a-learning-ecosystem. - (accessed July, 11, 2019)

[6] V. Orlova, I. Ilin, S. Shirokova, Management of port industrial complex development: Environmental and project dimensions (2018) MATEC Web of Conferences, 193, article № 05055. DOI: $10.1051 /$ matecconf/201819305055

[7] The Components of a Digital Age Learning Ecosystem. // Website BYOT Network. $\quad-\quad 2014 . \quad-\quad 2$ URL https://byotnetwork.com/2014/07/06/the-components-of-a-digitalage-learning-ecosystem. - (accessed July, 11, 2019)

[8] The Learning Ecosystem. // Website The Aspen Institute. -URL: http://csreports.aspeninstitute.org/Task-Force-on-Learning-and-theInternet/2014/report/details/0046/Task-Force-Introduction-andChallenges. - (accessed July, 11, 2019)
[9] Modelling open education learning ecosystem. // Website Tihane $\begin{array}{lllll}\text { Wordpress. } & - & 2012 . & - & \text { URL: }\end{array}$ https://tihane.wordpress.com/2012/05/08/modelling-digital-learningecosystem. - (accessed July, 11, 2019)

[10] Renya, J. (2011). Digital Teaching and Learning Ecosystem (DTLE): A Theoretical Approach for Online Learning Environments. In G. Williams, P. Statham, N. Brown \& B. Cleland (Eds.), Changing Demands, Changing Directions. Proceedings ascilite Hobart 2011. (pp.1083-1088)

[11] Digital learning platforms transform education. // Website The Australian Business Review. - 2016. - URL: https://www.theaustralian.com.au/business/technology/digitallearning-platforms-transform-education/newsstory/7444cb4a32827454944bf1531be3bfbb. - (accessed July, 11, 2019)

[12] Chao-Tung Yang, Hsin-Chuan Ho, An e-Learning Platform Based on Grid Architecture, Journal of information science and engineering 21, 911-928 (2005)

[13] Ch. Bouras, A. Gkamas, V. Kapoulas, P. Lampsas, Th. Tsiatsos, A platform for the implementation of the services of an educational network

[14] Fuertes, Walter \& López de Vergara Méndez, Jorge \& Meneses, F. (2009). Educational Platform using Virtualization Technologies: Teaching-Learning Applications and Research Use Cases.

[15] Business Model Canvas Explained with Examples. // Website Expert Program Management. - URL: https://expertprogrammanagement.com/2018/10/business-modelcanvas-explained. - (accessed July, 11, 2019)

[16] I.V. Ilin, O.Y. Iliashenko, A.I. Klimin, K.M. Makov. Big data processing in Russian transport industry (2018) Proceedings of the 31st International Business Information Management Association Conference, IBIMA 2018: Innovation Management and Education Excellence through Vision 2020, pp. 1967-1971.

[17] Advantages of the Business Model Canvas. // Website Get2Growth. 2014. - URL: https://get2growth.com/business-model-canvas/. (accessed July, 11, 2019)

[18] Business Model Canvas. // Website Canvanizer. - URL: https://canvanizer.com/new/business-model-canvas. - (accessed July, 11, 2019)

[19] Benefits of Using Osterwalder Canvas Business Model. // Website Cloutos. - 2018. - URL: https://cloutos.com/osterwalder-canvasbusiness/. - (accessed July, 11, 2019)

[20] Business Model Canvas Tutorial // Website Canvanizer. - 2018. URL: https://canvanizer.com/how-to-use/business-model-canvastutorial. - (accessed July, 11, 2019)

[21] P. D. Long, Encyclopedia of Distributed Learning, Learning $\begin{array}{lll}\text { Management } & \text { Systems } & \text { (LMS), }\end{array}$ http://dx.doi.org/10.4135/9781412950596.n99

[22] LMS and LCMS: What's the Difference? // Website Efront. - 2013. URL: https://www.efrontlearning.com/blog/2013/05/lms-and-lcmswhats-the-difference.html. - (accessed July, 11, 2019)

[23] M. Olaniyan, D. Graham. Media Streaming for Technological Innovation in Higher Education. Handbook of Research on Transnational Higher Education. IGI Global, 2014. 691-712. Web. 15 Jul. 2019. doi:10.4018/978-1-4666-4458-8.ch035

[24] P. Nikolaos. Virtual Communities of Inquiry Encyclopedia of Information Science and Technology, Third Edition. IGI Global, 2015. 7564-7573. Web. 15 Jul. 2019. doi:10.4018/978-1-4666-5888-2.ch745

[25] Digital learning platforms: the future of global education? // Website Training. - 2016. - URL: https://trainingmag.com/digital-learningplatforms-future-global-education. - (accessed July, 11, 2019)

[26] 5 Imperative Benefits of Digital Education Platforms. // Website Medium. $\quad-\quad 2019 . \quad 2 \quad-\quad$ URL: https://medium.com/@LOLTOKEN_EIU.AC/5-imperative-benefitsof-digital-education-platforms-d77468b0bafd. - (accessed July, 11, 2019)

[27] Why Students Love Digital Learning Platforms. // Website Dexway. URL: https://www.dexway.com/why-students-love-digital-learningplatforms. - (accessed July, 11, 2019)

[28] 7 Benefits of Digital Learning. // Website Focusband. - 2017. - URL: https://focusband.com/7-benefits-digital-learning. - (accessed July, 11, 2019) 
[29] Digital Transformation: Make your employees an asset! // Website Shortways. - 2016. - URL: http://shortways.com/blog/digital/digitaltransformation-make-employees-asset. - (accessed July, 11, 2019)

[30] A. Kozlov, A. Teslya. (2017) Human factors for development of corporate internal social investments Portfolio. Advances in Intelligent Systems and Computing, 2017.

[31] I. Zaychenko, A. Smirnova, V. Kriukova. Application of Digital Technologies in Human Resources Management at the Enterprises of Fuel and Energy Complex in the Far North (2019) Advances in Intelligent Systems and Computing, 983, pp. 321-328.

[32] O.V. Kalinina, I.M. Zaychenko, S.S. Gutman. Concept of creating innovative mechanism of human resource development in Russia (2017) Proceedings of the 30th International Business Information Management Association Conference, IBIMA 2017 - Vision 2020 Sustainable Economic development, Innovation Management, and Global Growth, 2017-January, pp. 2708-2719.

[33] A. Dubgorn, I. Zaychenko, N. Grashhenko. A rationale for choosing the mechanism of public-private partnership for the sustainable development of social infrastructure facilities. MATEC Web of Conferences. Volume 170, 13 June 2018, Number 10562017
[34] The True Cost Of A Learning Management System. // Website eLearning. - 2017. - URL: https://elearningindustry.com/true-cost-ofa-learning-management-system. - (accessed July, 11, 2019)

[35] What are the cons of a business model canvas? // Website Quora. 2018. - URL: https://www.quora.com/What-are-the-cons-of-abusiness-model-canvas. - (accessed July, 11, 2019)

[36] A.I. Levina, A.D. Borremans, A.N. Burmistrov. Features of enterprise architecture designing of infrastructure-intensive companies (2018) Proceedings of the 31st International Business Information Management Association Conference, IBIMA 2018: Innovation Management and Education Excellence through Vision 2020, pp. 4643-4651.

[37] I.V. Ilin, V.I. Koposov, A.I. Levina. Model of asset portfolio improvement in structured investment products (2014) Life Science Journal, 11 (11), pp. 265-269.

[38] A.R. Bril, O.V. Kalinina, I.V. Ilin (2017) Economic Analysis of Projects in the Improvement of the HR Management System of Enterprises // Proceedings of the 29th International Business Information Management Association Conference - Sustainable Economic Growth, Education Excellence, and Innovation Management through Vision 2020 Pp. 2268-2277 